\title{
UM OLHAR SOBRE O POTENCIAL PEDAGÓGICO DA SERRA DO TORREÃO, JOÃO CÂMARA/RN
}

\author{
Aleson da Silva Fonseca ${ }^{1}$; Adriana de Souza Santos ${ }^{2}$
}

\section{RESUMO}

A Educação Ambiental (EA) pode ser considerada como um processo transformador, que visa intervir de forma direta nos hábitos e atitudes dos cidadãos. O objetivo desse trabalho foi diagnosticar o potencial didático de uso da Serra do Torreão como espaço não formal de ensino na EA por professores do município de João Câmara/RN. Para coleta de dados foi aplicado um questionário semiestruturado composto por 12 perguntas, sendo respondido por 14 professores. A análise do questionário demonstra que a maioria dos professores utilizam a serra como recurso pedagógico, porém de forma pontual, sem enfatizar a interdisciplinaridade. Contudo, a serra apresenta um grande potencial didático a ser aproveitado nas diferentes disciplinas, sendo uma área que pode auxiliar o professor e alunos no processo de ensino-aprendizagem.

Palavras-chave: Educação Ambiental. Espaço não formal. Recurso Didático. Prática Pedagógica. Caatinga.

\begin{abstract}
Environmental Education (EE) can be regarded as a transformative process, which aims to intervene directly in the habits and attitudes of citizens. The aim of this study was to diagnose the educational potential use of the Serra do Torreão as non-formal education space in EA by teachers in the municipality of João Câmara / RN. For data collection was used a semi-structured questionnaire composed of 12 questions being answered by 14 teachers. Analysis of the questionnaire shows that most teachers use the saw as an educational resource, but of form punctual, without emphasizing interdisciplinarity. However, the saw has great educational potential to be tapped in the different disciplines, and an area that can help teachers and students in the teaching-learning process.
\end{abstract}

Key words: Environmental education. Non-formal space. Didactic resource. Teaching Practice. Caatinga.

\section{INTRODUÇÃO}

A Educação Ambiental (EA) pode ser considerada como um processo transformador e conscientizador, que visa intervir de forma direta nos hábitos e atitudes dos cidadãos, a qual surge como um dos princípios da educação do século XXI, promovendo em âmbito escolar uma reflexão direta para a geração de uma nova postura crítica e participativa para conservação e proteção do meio ambiente, configurando-se como uma medida interdisciplinar (SILVA; JOIA, 2008).

\footnotetext{
${ }^{1}$ Universidade Federal do Rio Grande do Norte. E-mail: fonseca.aleson@gmail.com

${ }^{2}$ Universidade Federal do Rio Grande do Norte. E-mail: adss_santos@yahoo.com.br
} 
Os Parâmetros Curriculares Nacionais enfatizam a EA como sendo um eixo transversal, ou seja, deve ser abordado de forma interdisciplinar, de modo a garantir a compreensão do mundo, permitindo que os estudantes tenham competências necessárias para o exercício da cidadania (BRASIL, 2008). Silva e Joia (2008) ressaltam que existe um desafio para a EA ser aplicada nas instituições de ensino, uma vez que sua efetivação depende da participação coletiva, o que promoveria uma mudança na condição social dentro do ambiente escolar.

O caráter transdisciplinar da EA auxilia os processos educacionais, uma vez que pode levar o sujeito crítico a refletir sobre sua realidade local, promovendo a mudança dessa realidade (CHAGAS, 2011). Morales et al. (2012) afirmar que a EA procura uma nova conduta para uma racionalidade social alternativa, pautado na participação da diversidade cultural e subjetiva dos indivíduos quanto cidadão.

Para Carvalho (2012):

[...] a EA está efetivamente oferecendo um ambiente de aprendizagem social e individual no sentido mais profundo da experiência de aprender. Uma aprendizagem em seu sentido radical, a qual, muito mais do que apenas promover conteúdos e informações, gera processos de formação do sujeito humano, instituindo novos modos de ser, de compreender, de posicionar-se ante os outros e a si mesmo, enfrentando os desafios e as crises do tempo em que vivemos. (CARVALHO, 2012, p. 69)

Chagas (2011) afirma que a interação com o meio ambiente, e o modo de interação social, pessoal e transpessoal permite o desenvolvimento humano contribuindo para ecoformação. A autora define ecoformação como um processo contínuo pautado no respeito à natureza, embasado na experiência de uma convivência ecológica com meio natural. Essa relação com o espaço natural é responsável pelo fortalecimento das relações humanas com o meio ambiente (CARVALHO, 2012).

Vale destacar que para promover a EA dentro das escolas, é importante desenvolver estratégias capazes de atingir os alunos, para que estes se sensibilizem e adotem uma postura participativa e comprometida com as questões ambientais. Uma estratégia utilizada para trabalhar a EA é levar os estudantes para ambientes naturais, como áreas de proteção ambiental, ambientes considerados como espaços não formais de ensino. Uma vez que romper os muros da escola, possibilita que alunos e professores explorem os diversos ambientes de sua comunidade. 
ISSN- 1413-8638

E-ISSN - 2238-5533

v. 22 , n. 2, p. 228-244, 2017

A EA realizada em espaços não formais vem sendo adotado ao longo do tempo, a partir de sua utilização como forma de promover a sensibilização para conservação da natureza (REIS; SEMÊDO; GOMES, 2012). Segundo esses autores existem poucos recursos disponíveis para trabalhar a EA em espaços não formais, pois as Unidades Federais de Conservação (parques e reservas) em sua maioria não apresentam programas educacionais, destinando seus recursos na fiscalização e não na educação da população.

Todavia, destaca-se que as áreas de proteção ambiental permitem que os alunos possam compreender a dinâmica ambiental, garantindo um espaço de laser, de vivência antropogênica respeitando as espécies que ali vivem, no intuito de preservar o equilíbrio ecológico. Desenvolver atividades em ambientes naturais, trás ganhos ainda maiores, pois permite uma reflexão que pode levar a valorização daquele espaço. E para isso, se faz necessário um planejamento eficiente para que os objetivos da EA possam ser atingidos, garantindo a preservação, compreensão e valorização do meio ambiente (CONRADO; CHAGAS; SILVA, 2016).

A realidade local deve ser sempre levada em consideração para a prática da EA, atendendo aos aspectos históricos, culturais e sociais do público-alvo, garantindo o respeito às diferentes formas de vida, de cultura, fazendo uso de estratégias democráticas e de interação para estimular a solidariedade, a igualdade e o os direitos humanos (REIS; SEMÊDO; GOMES, 2012).

Um exemplo de valorização ambiental na prática da EA pode citar o bioma Caatinga, considerado o único bioma exclusivamente brasileiro, e corresponde a uma área de $734.478 \mathrm{~km}^{2}$ do território brasileiro (MMA, 2012). Devido a sua posição geográfica esse bioma apresenta altas temperaturas, solos rasos e cristalinos, baixos índices de chuvas e umidade, alta incidência solar com uma notável riqueza de espécies endêmicas (ROQUE, 2009). No entanto, a população dessa região acredita que a Caatinga é pouco diversa biologicamente, porém alguns estudos demonstram o enorme padrão de riqueza e diversidade biológica desse bioma (LEAL; TABARELLI; SILVA, 2010). Entretanto, a EA se faz importante para acabar com essa concepção. Partindo dessa premissa, é possível criar atividades interessantes em espaços que tenham potencial para trabalhar com vários conceitos ligados a temática socioambiental voltado para diversidade da Caatinga nordestina. 
No município de João Câmara, Rio Grande do Norte, encontra-se a Serra do Torreão, área que apresenta remanente de Caatinga. A Serra do Torreão (Figura 1), situada na comunidade do Corte, é uma formação geológica de 147 metros, a vegetação dominante é a Savana-Estépica Arborizada (SALGADO et al., 1981; IBGE, 2012), abrigando inúmeras espécies de fauna e flora típica do bioma Caatinga (TORQUATO, 2012). A comunidade do Corte fica distante em média três quilômetros da sede do município, é formado por famílias simples, inclusive com casas ainda de taipa, em que parte dos moradores sobrevive da agricultura de subsistência.

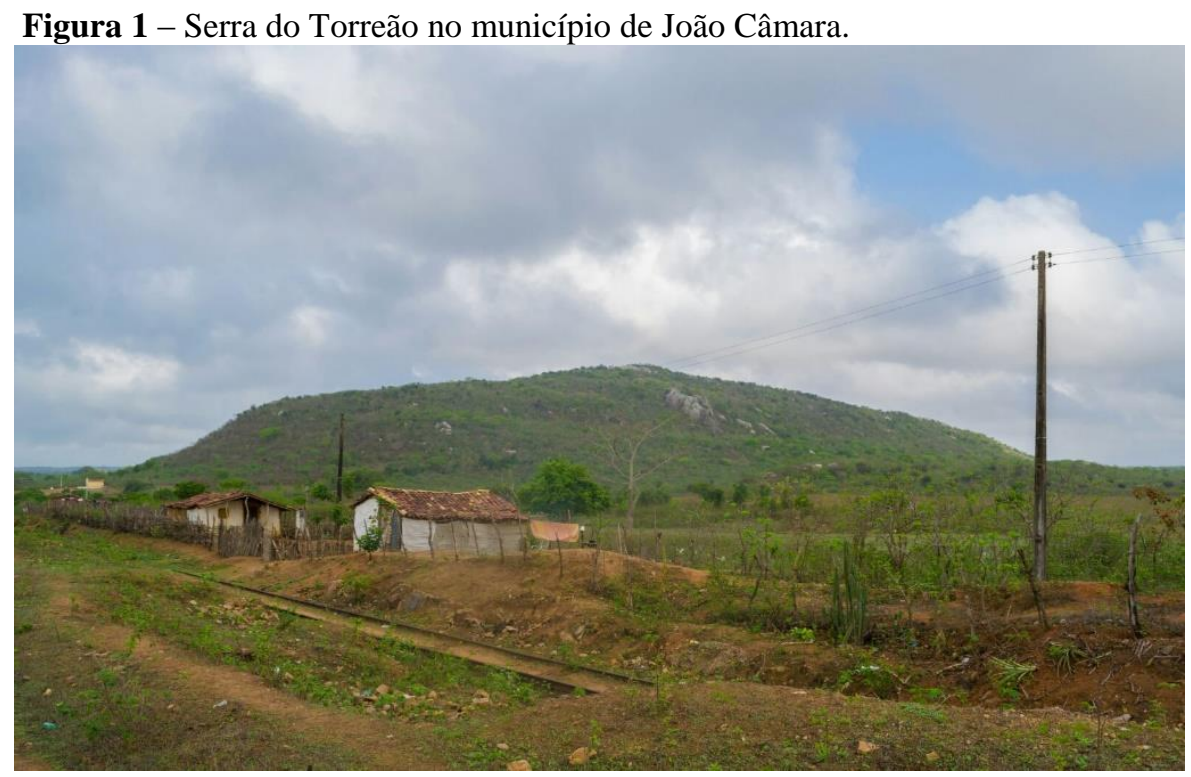

Fonte: Arquivo pessoal de Cleyson Avelino, Estudante de Licenciatura em Ciências Sociais.

De acordo com a Lei Orgânica do Município, do ano de 1990, a qual enfatizava em seu Art. 93 que a serra do Torreão seria transformada em uma reserva ecológica. E, portanto, para promover a sensibilização ambiental e a conservação desta área, caberia ao município estimular a criação de grupos ecológicos a fim de fiscalizar as ações humanas dentro de sua extensão (LOM, 1990).

Muito embora a Lei orgânica legitimar a serra como um espaço que merece atenção, tal ação não ocorreu da forma eficaz, pois nunca houve uma real fiscalização. Contudo, a versão atualizada da LOM (2015) não faz citação a serra como uma estação ecológica, apenas enfatiza em seu Art. 146 a preservação da serra, como demonstrado no inciso IX, que alega: "Garantir a preservação da Serra do Torreão, coibindo toda e 
ISSN- 1413-8638

E-ISSN - 2238-5533

v. 22, n. 2, p. 228-244, 2017

qualquer ação que ponha em risco a sua flora, fauna, recursos minerais e paisagismo e que possa alterar a sua forma original".

Embora sejam proibidas ações que venham a fragmentar a área da serra, os únicos instrumentos jurídicos que asseguram a sua proteção, além da LOM é o Plano Diretor Municipal (2006), que é o instrumento básico da política de desenvolvimento urbano na cidade, onde no município de João Câmara/RN ele tem como função, entre outras providências, de orientar e controlar as ações antrópicas próximas a serra, ainda que não haja o reconhecimento da área como Unidade de Conservação.

A serra do Torreão apresenta enorme potencial para explorar diversos conceitos ligados à temática ambiental, social, econômica, tais como a diversidade faunística e florística, a função religiosa e cultural, bem como a sua importância para o ecoturismo no município, portanto, se faz necessário um estudo que envolva a percepção dos professores sobre a região.

Pensando nisso, a presente pesquisa teve a finalidade de diagnosticar o potencial didático de uso da Serra do Torreão como espaço não formal de ensino na EA por professores do município de João Câmara/RN, realizando um levantamento de como esses docentes exploram os recursos culturais, históricos, filosóficos e naturais da serra a favor da sua disciplina.

\section{METODOLOGIA}

A pesquisa de cunho qualitativo foi realizada com professores de diversas áreas, de 5 escolas públicas e 1 escola privada do município de João Câmara/RN, sendo aplicado, para coleta dos dados, um questionário semiestruturado.

O questionário foi elaborado na plataforma Google e disponibilizado a 20 participantes através do link: <https://docs.google.com/forms/d/e/1FAIpQLSdOafX0gWgpe84HqlV9zzExJ_zht2UDpzFphl7Jt0hMrtg2Q/viewform?usp=send_form>.

O questionário apresenta doze perguntas (Quadro 1), sendo as cinco primeiras questões referentes ao perfil sócio profissional dos docentes, os sete questionamentos seguintes referem-se ao levantamento do uso e do potencial didático da Serra do Torreão, sendo que quatro questionamentos são fechados, em que se utilizou uma escala de avaliação intermediada pelo sistema binário de resposta: sim ou não; e três 
questionamentos são abertos em que os participantes complementaram ou justificaram suas respostas.

Quadro 1 - Estrutura do questionário semiestruturado aplicado aos professores

\begin{tabular}{|l|l|}
\hline \multicolumn{1}{|c|}{ EIXOS } & \multicolumn{1}{|c|}{ QUESTIONAMENTOS } \\
\hline Perfil sócio profissional & Idade; \\
Gênero sexual; \\
Disciplina que ministra; \\
Carga horária; \\
Tempo de experiência;
\end{tabular}

Fonte: Arquivo pessoal.

O questionário foi disponibilizado entre o período de janeiro a agosto de 2016, sendo divulgado aos professores através das redes sociais (Facebook e WhatsApp), de forma aleatória. Para preservar identidade dos entrevistados, optou-se em classificar os participantes da pesquisa por "entrevistados" de forma abreviada de ENTR 1, ENTR 2, ENTR 3, respectivamente, de acordo com o retorno dos questionários, seguidos do ano da resposta. Sendo assim, os fragmentos representativos das respostas dos professores foram transcritos, mas preservando a identidade dos mesmos.

Para análise dos dados foi utilizado à técnica de análise de conteúdos de acordo com Bardin (2010), a qual envolve três fases: a pré-análise, a exploração do material, e a análise e interpretação dos resultados.

\section{RESULTADOS E DISCUSSÕES}

Dos 20 participantes contatados 14 retornaram a pesquisa, destes $93 \%$ lecionam em escolas públicas e 7\% ensinam em escola privada. Em relação às cinco instituições de ensino público identificadas nesta pesquisa encontram-se as escolas estaduais e municipais: E. E. Capitão José da Penha; E. E. Francisco de Assis Bittencourt; E. E. 
Marluce Lucas; E. E. Antônio Gomes; E. M. Cicero Varela. Quanto à escola privada identificou-se apenas o Colégio Objetivo (Unidade de João Câmara).

Quadro 2 - Caracterização do perfil sócio profissional dos participantes

\begin{tabular}{|l|c|c|c|c|c|c|}
\hline ENTR & Gênero & Idade & $\begin{array}{c}\text { Tempo de } \\
\text { experiência }\end{array}$ & $\begin{array}{c}\text { Carga } \\
\text { horária }\end{array}$ & Disciplina & $\begin{array}{c}\text { Usou a } \\
\text { Serra }\end{array}$ \\
\hline ENTR1 & Fem. & 27 & 5 anos & $30 \mathrm{hs}$ & História & Sim \\
\hline ENTR2 & Mas. & 30 & 5 anos & $32 \mathrm{hs}$ & Matemática & Não \\
\hline ENTR3 & Fem. & 37 & 10 anos & $30 \mathrm{hs}$ & Geografia & Sim \\
\hline ENTR4 & Fem. & 36 & 6 anos & $20 \mathrm{hs}$ & Português & Sim \\
\hline ENTR5 & Fem. & 27 & 3 anos & $10 \mathrm{hs}$ & História & Sim \\
\hline ENTR6 & Fem. & 26 & 1 ano & $30 \mathrm{hs}$ & História & Não \\
\hline ENTR7 & Mas. & - & 5 anos & $30 \mathrm{hs}$ & Filosofia & Sim \\
\hline ENTR8 & Fem. & 32 & 10 anos & $60 \mathrm{hs}$ & Ciências/ & Sim \\
\hline ENTR9 & Fem. & 27 & 5 anos & $27 \mathrm{hs}$ & Sociologia/ & Não \\
\hline ENTR10 & Mas. & 42 & 8 anos & $30 \mathrm{hs}$ & Matemática & Não \\
\hline ENTR11 & Mas. & 27 & 9 anos & $20 \mathrm{hs}$ & História & Sim \\
\hline ENTR12 & Fem. & 25 & 1 ano & $30 \mathrm{hs}$ & Ciências & Não \\
\hline ENTR13 & Fem. & 56 & 35 anos & $30 \mathrm{hs}$ & Português & Sim \\
\hline ENTR14 & Mas. & 40 & 12 anos & $40 \mathrm{hs}$ & História & Não \\
\hline
\end{tabular}

Fonte: Arquivo pessoal.

A caracterização do perfil sócio profissional dos entrevistados identifica uma faixa etária variável entre 25 e 56 anos de idade, observa-se que a maioria é do sexo feminino (64\%), enquanto que 36\% são do sexo masculino (Quadro 2). Entre os participantes, constatou-se que a maioria ministra a disciplina de História (31\%), os demais ministram as disciplinas de Filosofia, Língua Portuguesa e Matemática (13\%, cada), Ciências (12\%), os outros 6\% ministram as matérias de Biologia, Geografia e Sociologia, sendo observado que alguns professores ministram mais de uma disciplina. Observa-se ainda que o tempo de experiência varia entre 1 a 35 anos, e a carga horária apresentou variação entre 10-60 horas semanais. Identificou-se ainda que 57\% já utilizou a serra com objetivos educacionais.

Em relação aos questionamentos fechados, com respostas binárias entre sim ou não, observou-se que todos os professores (100\%) concordam que a Serra do Torreão 
apresenta um potencial didático que possibilita que o professor explore diversos temas a partir de um único espaço.

Espaços naturais, como a Serra do Torreão, são ambientes dotados de inúmeras possibilidades de atividades, seu uso como recurso didático possibilita o reconhecimento da importância biológica e do equilíbrio ambiental, que são elementos básicos para a preservação à vida. Com o desenvolvimento da percepção ambiental os laços do homem com a natureza se solidificam (CHAGAS, 2011), promovendo assim à mobilização social em prol a defesa da área, coibindo as ações que ponham em risco a integridade ecológica.

Quando questionados se a escola já utilizou em algum momento os recursos naturais, culturais, históricos e filosóficos da serra como ferramenta auxiliadora no processo de ensino e aprendizagem, 86\% respondeu que "sim”. Para Pivelli e Kawasaki (2005), espaços como museus, parques, jardins botânicos, zoológicos, aquários são excelentes espaços para ampliação de conhecimentos que não se restringe apenas aos limites da escola.

Em se tratando das possibilidades de uso da serra, quanto aos aspectos ligados a história, os professores podem abordar a importância da serra e os conflitos sociopolíticos envolvendo a mesma. Torquato (2012) destaca que muitas casas foram construídas com madeiras retiradas de árvores próximas a Serra do Torreão, além disso, esse espaço sofreu por anos a exploração dos seus recursos geológicos, onde no passado foi usado para extração de pedras para pavimentação da cidade.

Embora essa exploração vir de anos, a população nunca permitiu bem esse tipo de utilização, ficando a serra como um espaço para visitação e para atividades religiosas, onde se comemora todos os anos no dia 20 de janeiro, os festejos de São Sebastião, levando muitos fiéis a caminhar em procissão até a capela que fica próximo a serra, em seguida sobem o Torreão como uma etapa de suas promessas (TORQUATO, 2012). No entanto, essa atividade religiosa leva o descarte inadequado de resíduos sólidos na área, pois à medida que as pessoas vão caminhando nas trilhas, vão sendo descartados garrafas de plástico de água mineral, sacos, papéis e dentre outros materiais que não são recolhidos pelos organizadores do evento, nem muito menos pelo poder público, e acabam presos à vegetação o que pode vir a interferir na dinâmica ecológica da área (FONSECA; SANTOS, 2016). 
O próprio fato de a serra ser um espaço religioso pode ser explorado por professores de História, enquanto que os professores de Filosofia, Geografia, Matemática, Ciências, Biologia e Sociologia poderia explorar esses conflitos sociais, políticos, econômicos e ambientais, isso garante a implantação dos objetivos traçados na Lei de diretrizes e bases da educação, Lei 9.394/96 no Art. 32, incisos II e III diz que cabe ao Ensino Fundamental proporcionar ao aluno:

"II - a compreensão do ambiente natural e social, do sistema político, da tecnologia, das artes e dos valores em que se fundamenta a sociedade; III - o desenvolvimento da capacidade de aprender, tendo em vista a aquisição de conhecimentos e habilidades e a formação de atitudes e valores; " (BRASIL, 2016, p.17).

Ao questionar se os professores apresentam a intenção e interesse em usar a serra em suas disciplinas, $86 \%$ disseram que "sim". Apesar desse resultado representar a maioria, isso ainda mostra que falta muito para que professores consigam associar os conteúdos sistematizados com as problemáticas locais, visto que apenas 56\% desses professores já utilizaram a serra com objetivos educativos. Essa associação entre conteúdos e as problemáticas locais possibilita aos alunos se tornarem agentes ativos dentro desse contexto, sendo capaz de opinar e tomar decisões (SOUZA; CERATI, 2013).

Entre os questionamentos abertos, inquiria se a serra poderia ser um espaço para trabalhar a EA, todos concordaram que sim (100\%), e justificaram suas respostas destacando a importância da preservação desse ambiente que tem grande relevância social para a população e ainda apresenta uma rica diversidade de espécies. Foram identificadas quatro categorias de resposta na análise das justificativas dos professores: conscientização ambiental (28,5\%); diversidade biológica (36\%); diversidade biológica e conscientização ambiental (21,5\%); e identidade cultural, histórica e natural (14\%) (Quadro 3).

\begin{tabular}{|c|c|l|}
\hline CATEGORIAS & $\%$ & \multicolumn{1}{|c|}{ FRAGMENTOS DE RESPOSTAS } \\
\hline Conscientização ambiental & $28,5 \%$ & $\begin{array}{l}\text { "Sim, podemos utilizar para conscientizar os alunos a } \\
\text { necessidade de preservar o espaço e as formas de vida } \\
\text { que ali vivem". (ENTR1, 2016). } \\
\text { "Sim, os alunos precisam compreender que a } \\
\text { conservação vem de pequenas atitudes e } \\
\text { principalmente de cuidar do que está próximo de seu } \\
\text { dia-a-dia. A Serra do Torreão permite que possamos }\end{array}$ \\
\hline
\end{tabular}




\begin{tabular}{|c|c|c|}
\hline & & $\begin{array}{l}\text { trabalhar a conscientização dos alunos, pois de nada } \\
\text { vale falar em preservar a Amazônia se não se preservar } \\
\text { o que existe em nosso "quintal". (ENTR12, 2016) }\end{array}$ \\
\hline Diversidade biológica & $36 \%$ & $\begin{array}{l}\text { "Sim. Lá existe uma grande diversidade de animais e } \\
\text { plantas, o que pode ser usado nas aulas de maneira } \\
\text { clara e prática, saindo tradicional". (ENTR2, 2016). } \\
\text { "Sim. E um espaço muito importante para nossa cidade } \\
\text { e região onde pode-se trabalhar a fauna e a flora local, } \\
\text { onde já foi encontrado espécies que não era conhecida, } \\
\text { espécies que estão desaparecendo na nossa região e } \\
\text { precisamos preservá-las". (ENTR3, 2016). }\end{array}$ \\
\hline $\begin{array}{l}\text { Diversidade biológica e } \\
\text { conscientização ambiental }\end{array}$ & $21,5 \%$ & $\begin{array}{l}\text { "Sim, tendo em vista a grande diversidade que existe. } \\
\text { Além da questão da preservação ambiental que será } \\
\text { possível através da educação ambiental". (ENTR8, } \\
2016 \text { ). } \\
\text { "Sim. Trata-se de um espaço altamente propício para } \\
\text { suscitar inúmeros debates sobre conservação, sobre a } \\
\text { fauna e flora locais e consciência ambiental". } \\
\text { (ENTR11, 2016). }\end{array}$ \\
\hline $\begin{array}{l}\text { Identidade cultural, histórica } \\
\text { e natural }\end{array}$ & $14 \%$ & $\begin{array}{l}\text { "Sim. Como monumento natural que é, o torreão, além } \\
\text { de se configurar como cartão postal da cidade, é } \\
\text { referência para a região do Mato Grande. Além disso, } \\
\text { para a vida das pessoas comuns da cidade é identidade } \\
\text { local, cultural e ambiental. Partindo deste princípio, } \\
\text { reconhecendo ainda muitos outros não citados, } \\
\text { justifica-se sua importância como riqueza natural e } \\
\text { ferramenta pedagógica". (EMTR7, 2016). } \\
\text { "Sim. Acredito que a serra do Torreão seria um espaço } \\
\text { muito bacana para aulas de História, Geografia, } \\
\text { Biologia e Ecologia. Trata-se de uma área dotada de } \\
\text { potenciais para trabalhar temas relacionados à cultura, } \\
\text { história local, formação de paisagens e meio } \\
\text { ambiente". (ENTR9, 2016). }\end{array}$ \\
\hline
\end{tabular}

Quadro 3 - Categorização e fragmentos de respostas referentes à justificativa dos professores sobre a Serra do Torreão ser um espaço para trabalhar a EA.

Fonte: Arquivo pessoal.

$\mathrm{Na}$ categoria "conscientização ambiental", os professores citam como justificativa a possibilidade de trabalhar a sensibilização ambiental na serra, pois é um espaço natural, porém não enfatizam a importância dessa preservação para fauna e flora deste ambiente, bem como para a preservação de recursos naturais relevantes ao futuro da civilização. Quanto à categoria "diversidade biológica", os professores enfatizam nas suas justificativas a diversidade de fauna e flora existente na região, e mais uma vez não citam a preservação dos recursos naturais. A categoria que engloba a "diversidade biológica e a conscientização ambiental" na mesma resposta é caracterizada pelas características citadas anteriormente nas duas categorias, sendo enfatizadas as duas justificativas. A quarta categoria "identidade cultural, histórica e natural”, enfatiza que a 
serra é uma referência da região e que merece proteção, preservando desta forma a história e cultura.

Durante anos, o discurso e a prática em poucos momentos andaram juntos, e em alguns momentos a serra sofreu com as ações humanas. Os relatos dos moradores apontam a instalação de uma pedreira que chegou inclusive a interferir em uma área no ano de 2011. Entretanto, a sociedade civil se organizou e conseguiu paralisar suas atividades. É diante dessas problemáticas que a EA se torna urgente, primeiro pelo fato de que é uma região semiárida da Caatinga, e vem sofrendo com o processo de desertificação, o qual é agravado pela ação antrópica (SOUZA; ARTIGAS; LIMA, 2015); em segundo, pelo fato de existir uma lacuna referente à carência de informações, que promova o empoderamento maior da sociedade e dos órgãos públicos.

A questão seguinte perguntava se a Serra do Torreão pode ser utilizada como um espaço não formal de ensino em sua disciplina, $86 \%$ respondeu que "sim", e ainda destacaram que já haviam usado o espaço para trabalhar conceitos em suas disciplinas, ou usaram as lendas locais como tema de aulas, como destacado nas respostas dos entrevistados 3, 8 e 11:

\footnotetext{
“Sim. Já trabalhei no tema paisagem, usando como exemplo de paisagem natural, cartão postal do nosso município e como exemplo para explicar a ideia de pertencimento, o conceito de lugar..." (ENTR3, 2016).

"Sim, pode-se trabalhar a questão histórica, da biodiversidade através de coleta de dados, fotografias, relatórios" (ENTR8, 2016).

"Sim. A Serra do Torreão não possui apenas um valor ecológico inestimável. Este valor perpassa também pela própria História Local do Município de João Câmara. Existem, por exemplo, várias lendas e estórias populares que tem como cenário a referida Serra" (ENTR11, 2016).
}

A união de aspectos locais e a EA garantem que o conhecimento seja significativo, e isso gera resultados interessantes, pois o aluno aproxima-se do objeto de estudo e percebe que ele está fazendo parte de um sistema integrado, que chamamos de natureza. Sendo assim, unir aspectos ligados a serra e a EA ajuda na garantia da formação para exercício da cidadania, valorizando aspectos culturais e as identidades dos diferentes grupos sociais (MMA, 2004).

Carvalho (2012, p. 37) ressalta que "exige um esforço de superação da dicotomia entre natureza e sociedade, para poder ver as relações de interação 
permanente entre a vida humana social e a vida biológica da natureza”. Neste sentido, Tamaio e Layrargues (2014) deixa claro que o trabalho primordial da Educação Ambiental é de fortalecer as conexões identitárias da comunidade com relação à área.

Alguns professores apontaram que a serra pode ser um espaço para construção de ideias e valores, como visualizado na resposta de ENTR7:

"Sim. O homem que pensa necessita de referências para o desenvolvimento de suas ideias. Filosoficamente considerado, pode-se considerar o Torreão, mais do que um simples espaço geográfico, mas ainda como espaço intelectual (sentido metafísico) para a formação de opinião (ENTR7, 2016).

Pautado no discurso do professor, a própria Lei $n^{\circ}$ 9.795/99 que dispões sobre a Política Nacional de Educação Ambiental ressalva em seu Art. $1^{\circ}$ que a Educação Ambiental é entendida como:

“[...] os processos por meio dos quais o indivíduo e a coletividade constroem valores sociais, conhecimentos, habilidades, atitudes e competências voltadas para a conservação do meio ambiente [...]”. (BRASIL, 2016, p.01)

A EA é parte do processo de formação de um sujeito crítico e participativo, dotado de valores éticos, voltados à conservação da natureza e o seu próprio bem-estar. Tamaio e Layrargues (2014) faz um alerta sobre os argumentos conservacionistas da EA em ambientes com potencial para conservação ao afirmarem que esses espaços não devem ser encarados como espaços intocados, que ao invés de estimular o sentimento de pertencimento, acaba por inibir a ação humana, negando os múltiplos usos culturais por parte da população. Por outro lado, os autores deixam claro que é correto inibir as ações que venham a por em risco a integridade biológica da área.

Para Diegues (2008) negar a relação humana com esses espaços ecológicos é privar os sujeitos do sentimento de pertencimento e com esse sentimento é possível trabalhar os conceitos em EA que possam vir a estimular uma proteção que vise à inibição do mau uso dos recursos naturais.

Ainda foram destacadas as dificuldades de trabalhar a EA, como visualizado na fala do ENTR6:

"Honestamente falando, não! Em virtude de alguns fatores, principalmente porque meus alunos são integralmente do turno noturno, então, por ser um público estudante-trabalhador vejo algumas barreiras para aplicar este 
método. Mas, podemos trabalhar teoricamente a história da Serra do Torreão, os mitos e lendas a cerca da sua construção histórica" (ENTR6, 2016).

Infelizmente, os alunos desse turno são compostos, em sua grande maioria, de pessoas que trabalham durante o dia (SILVA; MARTINS, 2007), e só tem a noite como único momento para estudar. Por isso a dificuldade do professor em explorar o espaço da serra como espaço não formal. Embora, o docente reconheça essa barreira, o mesmo consegue explorar em sala alguns conteúdos que envolvem a história local.

Em seguida foi questionado se algum aluno já teria usado a Serra do Torreão na elaboração de algum trabalho em sua disciplina, 57\% afirmaram que sim, e destacaram que alguns alunos desenham a serra retratando lendas, crendices, além de terem abordado questões ligadas às características do relevo, aspectos ecológicos e de preservação ambiental. Sobretudo, teve um entrevistado que reconheceu a importância dessa pesquisa:

"Sim. No referido caso trouxeram imagens mostrando o Torreão como ponto turístico da cidade de João Câmara [...]. Além disso, também utilizam bastante como exemplo durante as aulas, e pedem para que os professores os levem até lá. A iniciativa de desenvolver essa pesquisa certamente já possibilita que os docentes da região vejam a Serra do Torreão com um olhar diferente" (ENTR7, 2016).

Nota-se com esses questionamentos que a parte histórica, cultural, filosófica e natural da Serra do Torreão encontra-se sempre presente nos conteúdos ministrados por esses docentes. Porém, observou-se nas justificativas dos professores, que os mesmos apenas relacionam a serra com a EA em relação à biodiversidade do local, não sendo citada a importância do manejo e da recuperação dos fatores bióticos e abióticos, essenciais à sobrevivência da diversidade de fauna e flora da área, nem muito menos as questões referentes à poluição por resíduos sólidos que se tornou crescente nos últimos anos. E que infelizmente, vem se configurando uma realidade crescente.

Em relação aos $43 \%$ que respondeu "não", esse resultado pode apontar que falta por parte de professores e alunos a valorização do espaço local, como algo dotado de história e rico em aspectos pedagógicos que podem ser explorados por todos de forma a caracterizar a interdisciplinaridade em sala. Cuba (2010) relata que embora a EA seja um tema transversal de extrema importância muitos professores não se sentem na obrigação e nem preparados para abordá-la, e acabam ficando presos aos conteúdos que lhes são estabelecidos, os quais muitas vezes não conseguem concluí-los até o fim do 
ano letivo, por serem extensos demais, deixando que a EA seja ministrada pelo professor de biologia/ciências.

Quando questionados se os professores tinham interesse em usar a Serra do Torreão em sua disciplina, observou-se que a resposta negativa adveio de dois participantes $(\approx 14 \%)$, professor de Matemática e História. Portanto inferiu-se que de acordo com a disciplina que ministra, esses professores apresentam dificuldades em associar conceitos das referidas disciplinas de ordem educacional prática ou teórica envolvendo fenômenos relacionados ao meio ambiente. Caldeira (2001) enfatiza que a matemática pode oferecer métodos, sistemas, procedimentos e ferramentas para compreender os fenômenos relacionados ao meio ambiente, além de propiciar aos estudantes a compreensão de seu verdadeiro papel como cidadão e transformador social. Contudo, existe uma carência em material que sirvam como referencial para a formação desse professor, que possibilitem a transcendência da matemática de uma ciência isolada para uma ciência abrangente, que relacione questões mais amplas que propiciem a reflexão e a crítica sobre os fenômenos naturais.

\section{CONSIDERAÇÕES FINAIS}

O presente trabalho considera que a Serra do Torreão apresenta um grande potencial didático a ser aproveitado nas diferentes disciplinas, sendo uma área que pode auxiliar o professor e alunos no processo de ensino-aprendizagem, garantindo um espaço diferenciado para trabalhar conceitos da EA e ainda associá-los a vida cotidiana dos estudantes, garantindo a aprendizagem não só de conceito sistematizados, mas também de informações que contribui na formação de um cidadão crítico e participativo.

Em se tratando de EA, a serra é uma área que pode ser usada para sensibilização ambiental por meio de trilhas interpretativas. Atividades de laser são ideias que podem ser adotadas por várias instituições de ensino, que desejam trabalhar o desenvolvimento sustentável e a conservação ambiental, valorizando a história local em um espaço que está acessível a todos, mas que vem sofrendo com o descaso público.

Apesar de ser um estudo exploratório, a pesquisa demonstra que esses professores não atuam de forma interdisciplinar, nem dando ênfase ao eixo transversal, 
e sim que exploram os recursos culturais, históricos, filosóficos e naturais da serra a favor de suas disciplinas de forma isolada.

A Serra do Torreão é um excelente espaço para construção de conceitos e exemplificação de conteúdos, mas cabe aos professores reconhecerem esse espaço como uma área dotada de história e importância socioambiental. Vale ressaltar que, a maneira como a sociedade vê a serra, é resultado da carência de trabalhos didáticos voltados à valorização desse ecossistema, seja para preservação histórica, social, econômica, religiosa e ambiental.

Enfatiza-se, portanto a necessidade de intervenção junto ao corpo docente e a comunidade escolar, na elaboração de atividades interdisciplinares relacionadas ao eixo transversal meio ambiente. Isso é de fundamental importância para atingir a sensibilização, que é um dos princípios da Educação Ambiental.

Além disso, espera-se que as intervenções pedagógicas contribuam de forma significativa no reconhecimento da importância ambiental e sociocultural da Serra do Torreão por parte do poder público, o que contribuirá para o desenvolvimento de políticas públicas que visem à conservação da área, através de instrumentos jurídicos, a partir da sua transformação em Unidade de Conservação, sobretudo com a implantação de atividades de EA, o que estimulará o uso consciente dos recursos naturais, o sentimento de pertencimento, bem como a biofilia. E desta forma, intensificar o empoderamento e a mobilização social para melhoria do espaço da Serra do Torreão.

\section{REFERÊNCIAS}

BARDIN, L. Análise de conteúdo. Lisboa, Portugal: Edições 70 LDA, 2010.

BRASIL. Lei Federal $\boldsymbol{N}^{\boldsymbol{0}}$ 9.394, de 20 de dezembro de 1996: Estabelece as diretrizes e bases da educação nacional. Disponível em: <http://www.planalto.gov.br/ccivil_03/leis/L9394.htm>. Acesso em: 27 ago. 2016.

BRASIL. Lei Federal No 9.795, de 27 de abril de 1999: Dispõem sobre a educação ambiental, institui a Política Nacional de Educação Ambiental e dá outras providencias. Disponível em: <http://www.mma.gov.br/port/conama/legiabre.cfm?codlegi=321>. Acesso em: 27 ago. 2006.

BRASIL. Lei $\mathbf{n}^{\mathbf{0}} \mathbf{9 . 9 8 5}$, de 18 de julho de 2000. Regulamenta o art. 225, § 1o, incisos I, II, III e VII da Constituição Federal, institui o Sistema Nacional de Unidades de Conservação da Natureza e dá outras providências. Diário Oficial da União. Brasília, 19 jul. 2000. 
BRASIL. Os diferentes matizes da educação ambiental no Brasil: 1997-2007. Brasília, DF: Ministério do Meio Ambiente, 2008.

CALDEIRA, A. D. Educação ambiental e suas implicações na formação do professor de matemática. RPD - Revista Profissão Docente, Uberaba, v. 1, n. 1, p. 24-35, jan./abr., 2001.

CARVAlHO, I. C. M. Educação Ambiental: a formação do sujeito ecológico. São Paulo: Cortez, 2012.

CHAGAS, K. K. N. Por uma Educação Ambiental corporalizada: a emoção em trilhas interpretativas. Natal: IFRN, 2011.

CONRADO, L. M. N.; CHAGAS, M. M.; SILVA, V. H. Educação Ambiental e interdisciplinaridade: conceitos e diálogos na formação de professores. Natal: Offsert Editora, 2016.

CUBA, M. A. Educação ambiental nas escolas. ECCOM, v. 1, n. 2, p. 23-31, jul/dez., 2010.

DIEGUES, A. C. O mito moderno da natureza intocada. São Paulo: Hucitec NupaubUSP/CEC, 2008.

FONSECA, A. S.; SANTOS, A. S. Educação Ambiental na formação do sujeito ecológico no Escotismo. In: Congresso Nacional de Educação, 3., 2016, Natal. Anais... Natal: Editora Realize, 2016. p. 01-12.

IBGE. Manual Técnico da Vegetação Brasileira. Rio de Janeiro: IBGE-CDDI, 2012.

LEAL, I. R.; TABARELLI, M.; SILVA, J. M.C. Ecologia e conservação da Caatinga. Recife: Editora Universitária da UFPE, 2003.

LEI ORGÂNICA DO MUNICÍPIO. Capítulo IV de 21 de setembro de 2015. Do Meio Ambiente. Câmara Municipal de João Câmara. Disponível em:< http://www.camaramunicipaljc.com.br/index.php>. Acesso em: 17 fev. 2015.

LEI ORGÂNICA DO MUNICÍPIO. Capítulo VI de 03 de abril de 1990. Do Meio Ambiente. Câmara Municipal de João Câmara. Disponível em:< http://www.camaramunicipaljc.com.br/index.php>. Acesso em: 17 fev. 2015.

MINISTÉRIO DO MEIO AMBIENTE. Biodiversidade Brasileira: Avaliação e identificação de áreas e ações prioritárias para conservação, utilização sustentável e repartições dos benefícios da biodiversidade nos biomas brasileiros. Brasília: Ministério do Meio Ambiente. 2012.2 Disponível em:<http://www.mma.gov.br/estruturas/chm/_arquivos/biodivbr.pdf >. Acesso em: 17 mar. 2016.

MINISTÉRIO DO MEIO AMBIENTE. Identidades da educação ambiental brasileira. Diretoria de Educação Ambiental; Philippe Pomier Layrargues (coord.). Brasília: Ministério do Meio Ambiente, 2004. 156 p. 
MORAlES, A. G. et al. Educação Ambiental e Multiculturalismo. Ponta Grossa: Editora UEPG, 2012.

PLANO DIRETOR DO MUNICÍPIO. Lei no 241, de 10 de outubro de 2006. Institui o Plano Diretor do Município de João Câmara. Disponível em:< http://www.camaramunicipaljc.com.br/legislacaocategoria.php?catl_slug=Leis\%20Municipais>. Acesso em: 13 jul. 2017.

REIS, L. C. L.; SEMÊDO, L. T. A. S.; GOMES, R. C. Conscientização Ambiental: da Educação Formal a Não formal. Revista Fluminense de Extensão Universitária, Vassouras, v. 2, n. 1, p. 47-60, jan./jun., 2012.

ROQUE, A. A. Potencial de uso dos recursos vegetais em uma do semi-árido do Rio Grande do Norte. 2009. 79 p. Dissertação (Mestrado em Desenvolvimento e Meio Ambiente) - Universidade Federal do Rio Grande do Norte, Natal, 2009.

SALGADO, O. A.; JORDY-FILHO, S.; CARDOSO-GONÇALVES, L. M. Vegetação: As regiões fitoecológicas, sua natureza e seus recursos econômicos; Estudo fitogeográfico. In: Brasil. Projeto RADAMBRASIL. Folhas SB. 24/25 Jaguaribe/Natal. Rio de Janeiro: Projeto RADAMBRASIL. p. 485-544, 1981.

SILVA, E. P.; MARTINS, P. T. A. Educação ambiental no período noturno em Curitiba (PR): estudo de caso no Colégio Estadual Professor Guido Straube. Revista Espaço Acadêmico, n. 70, mar., 2007.

SILVA, M. S. F. \& JOIA, P. R. Educação Ambiental: a participação da comunidade na coleta seletiva de resíduos sólidos. Revista Eletrônica da Associação dos Geógrafos Brasileiros, Três lagoas-MS, n. 7, Mai., 2008.

SOUZA, A. Q.; CERATI, T. M. Educação ambiental e participação social na resolução de conflitos: estudo de caso em uma Unidade de Conservação urbana de São Paulo, Brasil. In: Encontro Nacional de Pesquisa em Educação em Ciências, 9., 2013, Águas de Lindóia. Anais... Águas de Lindóia: ABRAPEC, 2013. p. 01-08.

SOUZA, B. I. D.; ARTIGAS, R. C.; LIMA, E. R. V. D. The Caatinga and desertification. Mercator (Fortaleza), v. 14, n. 1, p. 131-150, jan./abr., 2015.

TAMAIO, I.; LAYRARGUES, P. P. Quando o parque (ainda) não é nosso. Educação ambiental, pertencimento e participação social no Parque Sucupira. Espaço \& Geografia, v. 17, n. 1, 145-182 p., 2014.

TORQUATO, A. Baixa-verde: outras histórias. João Câmara: Grafipel-Gráfica e Editora, 2012. Disponível em:<http://pt.scribd.com/doc/96464859/baixa-verde-outrashistorias-final\#scribd> Acesso em: 04 out. 2015. 